Original Research Paper

\title{
Molecular Characterization of Vaccine-Derived Mutants of Avian Metapneumoviruses Isolated from Turkeys in Egypt
}

\author{
${ }^{1}$ Abdel-Satar Arafa, ${ }^{1}$ Wessam Mady, ${ }^{2}$ Ahmed Hussein, ${ }^{2}$ Sabry Tamam and ${ }^{2}$ Hanafy Madbouly \\ ${ }^{I}$ National Laboratory for Veterinary Quality Control on Poultry Production, \\ Animal Health Research Institute, P.O. Box 264-Dokki, Giza-12618, Egypt \\ ${ }^{2}$ Virology Department Faculty of Veterinary Medicine, Beni-Suif University, Egypt
}

\author{
Article history \\ Received: 10-31-2014 \\ Revised: 11-24-2014 \\ Accepted: 13-06-2015 \\ Corresponding Author: \\ Abdel-Satar Arafa Mohamed \\ National Laboratory for \\ Veterinary Quality Control on \\ Poultry Production, Animal \\ Health Research Institute, P.O. \\ Box 264-Dokki, Giza-12618, \\ Egypt \\ Email: abd.arafa@gmail.com
}

\begin{abstract}
Avian metapneumovirus (aMPV) causes acute respiratory infection in turkeys with sudden onset and rapid spread in the infected flocks. Vaccinated flocks frequently showed clinical signs typical like the non-vaccinated flocks in Egypt, this situation suggests a virulent vaccine virus was circulating in the field. Oropharyngeal and nasal sinus swabs were collected from 100 turkeys from 10 commercial farms with mild to moderate respiratory signs. Virus isolation and propagation was done in SPF embryos of chicken eggs via yolk sac inoculation and further passed in Vero cells. RT-PCR for detection of aMPV was done on field samples as well as on virus isolates. Genotyping of viruses was done through RT-PCR targeting Fusion (F) and the surface Glycoprotein (G) genes and partial sequencing of PCR products was used for genetic and phylogenetic analyses. The results were compared with two live attenuated commercial vaccines commonly used in the field. Analysis of nucleotide and amino acid sequences for $\mathrm{F}$ and $\mathrm{G}$ genes indicated that they were very closely related to each other and belonging to B subtype of aMPV isolated from Europe. The Egyptian viruses were very close to $\mathrm{VCO} 3$ vaccine strain, indicating their possible origin. Phylogenetic analysis indicates clustering of the Egyptian field viruses with European strains of B subtype. These results support that they may have a common progenitor from vaccine strains and suggesting evidence of reversion of attenuated vaccine virus to virulence. This is the first report describing the emergence of vaccine-derived mutants from the B subtype aMPV in broiler turkeys in Egypt.
\end{abstract}

Keywords: Avian Metapneumoviruses, Vaccine-Derived Mutants, Molecular Characterization of $\mathrm{F}$ and G Genes, aMPV in Egypt

\section{Introduction}

Avian metapneumovirus (aMPV), former was described as Turkey Rhinotracheitis (TRT) in turkeys and Swollen Head Syndrome (SHS) in chickens (Gough, 2003). The aMPV is an important pathogen causing respiratory disease and egg drops in chickens and turkeys. It was first described in South Africa in 1978 (Buys et al., 1989) and subsequently several outbreaks followed in the early 1980s in continental Europe (Giravd et al., 1986; Hafez et al., 2000). The aMPV causes an acute respiratory tract infection both in turkeys and in chickens with a sudden onset and rapid spread through flocks (Anon, 1985). Clinical signs are often mild, but in the presence of secondary bacterial infections the disease can be very severe and even fatal.
The genome contains eight genes present in the same order shown in the other metapneumoviruses, 3-N-P-MF-M2-SH-G-L-5 and encodes 9 proteins, including Nucleoprotein $(\mathrm{N})$, Phosphoprotein $(\mathrm{P})$, matrix protein (M), Fusion protein $(\mathrm{F})$, second matrix protein (M2), small hydrophobic protein (SH), surface Glycoprotein (G) and a viral RNA-dependent RNA polymerase (L). All aMPV genes encode one viral protein, except the M2 gene, which encodes two proteins; M2-1 and M2-2 (Tanaka et al., 1995; Sugiyama et al., 2010). Although pneumoviruses have $\mathrm{F}$ protein that upholds cell fusion, these viruses do not have hemagglutination property or neuraminidase activity in their $\mathrm{G}$ attachment protein and that distinguishing them from the other paramyxoviruses (Collins and Gough, 1988). The $\mathrm{F}$ and $\mathrm{G}$ proteins are the two major antigens of aMPV, where the G protein is 
known to be the most variable protein in human respiratory syncytial virus, which is the prototype of pneumovirus (Johnson et al., 1987), the F protein is one of the major immunogens expressed on the surface of pneumoviruses and so it is important in inducing protective immunity (Yu et al., 1994).

Avian metapneumoviruses have been classified into four subtypes, including A, B, C and D based on nucleotide sequence analysis and neutralization with monoclonal antibodies (Cook et al., 1993; Bayon-Auboyer et al., 2000). Many countries reported different subgroups of aMPV, mainly A or B, like Israel, Mexico, Morocco, Jordan, Brazil, Japan and many European countries (Hafez et al., 2000; OIE, 2008). The aMPV has been circulating globally since 1978, reported in the United States from a commercial turkey farm in Colorado in 1996 and subsequently in Minnesota (Cook et al., 1999). Few reports described the incidence and distribution of aMPV in Egypt; however, it caused serious problems in turkey production and affected the performance of turkey pouts and chickens (Collins and Gough, 1988; Mahmoud et al., 2008). As aMPV causes a considerable economic loss, several attempts have been made to develop a live attenuated vaccine (Cook et al. 1989a; 1989b; Williams et al., 1991). Vaccination has been used to protect flocks from virus infections to a certain extent (Buys et al., 1989).

Nucleotide sequence analysis of the $G$ gene has been used for differentiating subtypes A and B and RT-PCR assays directed to the $\mathrm{F}$ and $\mathrm{M}$ genes are subtype specific and useful for detection of aMPV when subtype identity of the virus is known (OIE, 2008).

This work describes the molecular characterization of Avian metapneumoviruses isolated from infected turkey flocks in Egypt from 2008 to 2009 using partial sequencing of the $(F)$ gene and the $(G)$ gene and for differentiation between field and vaccine strains that was commonly applied in the field.

\section{Materials and Methods}

\section{Samples}

Oropharyngeal and nasal sinus swabs were collected from 100 turkeys from 10 commercial farms sourced from 3 Egyptian Governorates (Giza, Beni-Suif and Cairo) from 2008 to 2009 and named as Giza-1-5, 9, 10, Beni-Suif-6, 7 and Cairo-8. These flocks were vaccinated with different regimens, for example, 2 flocks (Giza-1 and Beni-Suif-7) with 2 vaccines (one day old live spray and inactivated combined ND+TRT s/c at 45 days) and two flocks (Giza-3, 4) with 3 vaccinations (1 killed then 2 live) and 1 non vaccinated flock (Cairo-8). Other flocks were vaccinated with at least one live attenuated vaccine.

The symptoms began from 10 days up to 2 months post last vaccination in vaccinated flocks and ranged from mild to moderate respiratory distress, facial edema and nasal discharge with sinusitis occasionally. The swabs were pooled from each farm (10swabs/pool) and immersed in Phosphate Buffer Saline (PBS) with antibiotic (Penicillin $0.5 \mathrm{U} / \mathrm{ml}$ and Streptomycin $0.5 \mathrm{mg} / \mathrm{ml}$ ) then centrifuged at $1000 \mathrm{xg}$ for $10 \mathrm{~min}$. The supernatant were passed through a $0.450 \mu \mathrm{m}$ membrane filter and kept at $80^{\circ} \mathrm{C}$ for virological and molecular diagnosis.

Vaccines: Two live attenuated commercial vaccines were used, Aviffa ${ }^{\circledR}$ and Nemovac ${ }^{\circledR}$. They were used for sequence comparison between field and vaccine strains. The vaccine strain (VCO3/60616 B subtype, accession number: AB548428) was used for sequence comparison.

Virus isolation and propagation: The pooled swabs from the 10 cases were inoculated in SPF embryos of chicken eggs via yolk sac route at 5-7 days old embryos and further passed in Vero cells for two successive passages using Minimum Essential Medium (MEM) supplemented with $10 \%$ fetal bovine serum containing penicillin $(0.5 \mathrm{U} / \mathrm{ml})$ and streptomycin $(0.5 \mathrm{mg} / \mathrm{ml})$.

\section{RT-PCR and Genetic Analysis}

The B subtype strain UK/8/94 (GenBank Accession number Y14294) was used as the standard for comparisons (Juhasz and Easton, 1994; Naylor et al., 1998).

RNAs were extracted from oropharyngeal and nasal swabs from each case for direct detection of aMPV and also to confirm virus isolation using RNA Extraction kit (QIAmp Viral RNA Mini kit, Cat. No. 52904, Qiagen, Valencia, Calif, USA). Reserve Transcription (RT) was performed using RT random hexamer primers or G6primer (Naylor et al., 1998) and AMV reverse transcriptase (Roche, Cat. No.13490320) according to the manufacturer's instructions, the RT reactions were done using $5 \mu \mathrm{L}$ of purified RNA in a $20 \mu \mathrm{L}$ reaction volume and this step was carried out on thermal cycler (T3, Biometra, Germany) with a thermal profile of $42^{\circ} \mathrm{C} / 30 \mathrm{~min}$ then $85^{\circ} \mathrm{C}$ for $5 \mathrm{~min}$.

Partial Fusion (F) and attachment (G) genes of aMPV were amplified by PCR with primers designed from consensus sequences of aMPV as follow: Polymerase Chain Reaction (PCR) was done in a final volume of 25 $\mu \mathrm{L}$ using PCR kit (ABgene-Thermo, UK) and $2 \mu \mathrm{L}$ of gene specific primers for $\mathrm{G}$ and $\mathrm{F}$ genes (Table 1) and 5 $\mu \mathrm{L}$ of cDNA. The RT-PCR for aMPV was based on sequences of the $G$ genes of $A$ and $B$ subtype viruses (Juhasz and Easton, 1994). The oligonucleotide, G6-, for priming the RT reaction, had sequence common to both subtypes and was used in the first PCR with oligonucleotide $\mathrm{G} 1+$, consequent to the beginning of the gene, that able to hybridize with RNA of both virus subtypes. The 444 base pairs (bp) product was used in a nested PCR with oligonucleotide G5 and able to hybridize to RNA of both subtypes with oligonucleotides G8+ A, specific for A subtype or G9+B, specific for B subtype, generating cDNAs of 268 and $361 \mathrm{bp}$, respectively (Naylor et al., 1997). 
Table 1. Primers used for F and G genes of aMPV

\begin{tabular}{lllll}
\hline Oligonucleotide & Sequence & Gene & Position & Reference \\
\hline G6- & CTGACAAATTGGTCCTGATT & G & 422 to 441 & Juhasz and Easton (1994) \\
G5- & CAAAGA A/GCCAATAAGCCCAG & G & 401 to 419 & \\
G8+ A & CACTCACTGTTAGCGTCATAG & G & 152 to 171 & \\
G9+ B & TAGTCCTCAAGCAAGTCCTCG & G & 68 to 87 & \\
G1 +A & GGGACAAGTATCTCTATG & G & 1 to 18 & \\
G1+ B & GGGACAAGTATCCAGATG & G & 1 to 18 & \\
F13- B & CCCGACTTTGTTGCTGCCAA & F & 1187 to 1206 & Naylor et al. (1998) \\
F11+B & GTCAGATTAGCCTCATGCTGAAC & F & 728 to 750 & \\
F10-B & AGGCTACCATGCTTACAGGG & F & 1116 to 1135 & \\
\hline
\end{tabular}

The nucleotide positions correspond to those in the sequence of type B strain UK/8/94, GenBank Accession number Y14294

The initial denaturation step was done at $94^{\circ} \mathrm{C}$ for $10 \mathrm{~min}$, followed by 35 cycles $\left(94^{\circ} \mathrm{C}\right.$ for $1 \mathrm{~min}, 51^{\circ} \mathrm{C}$ for $1 \mathrm{~min}$ and $72^{\circ} \mathrm{C}$ for $2 \mathrm{~min}$ ), a final elongation step at $72^{\circ} \mathrm{C}$ for $10 \mathrm{~min}$ was performed. The size of the amplicons was examined according to the target gene amplified (Tables 1 and 2) and according to the literature (Cavanagh et al., 1999). Each reaction was analyzed by $1.5 \%$ agar gel electrophoresis, stained with ethidium bromide and visualized under ultraviolet rays using $100 \mathrm{bp}$ DNA ladder as a marker (Qiagen, Germany) and sequenced using BigDye Terminator v3.1 Cycle Sequencing Kit with automatic sequencer (ABI-3130, Applied Biosystems, Foster City, CA). Nucleotide and amino acid sequence analysis as well as Phylogenetic analysis were carried out using the sequences of PCR products of $F$ and $G$ genes of the Egyptian isolates and vaccine strains. Multiple and pairwise sequence alignments were done by using the ClustalV algorithm of BioEdit software and MegAlign program from LaserGene Biocomputing Software Package (DNASTAR, Madison, WI). The phylogenetic tree of the $G$ gene was constructed using the neighbour-joining method of MEGA6 software (Tamura et al., 2013) as well as the evolutionary divergence between sequences was also estimated using the same software. The partial sequences of the $F$ gene and $\mathrm{G}$ gene of the Egyptian isolate (Giza-TRT-42009) were submitted to Genbank and accepted as HQ677586 and JX647840, respectively.

\section{Results}

\section{Results of RT-PCR for aMPV}

Eight samples (Giza-TRT-1, Giza-TRT-2, GizaTRT-3, Giza-TRT-4, Giza-TRT-5, Beni-Suif-TRT-7, Cairo-TRT-8 and Giza-TRT-10) were positive by RTPCR for direct detection of aMPV and showed two specific bands at $489 \mathrm{bp}$ and $408 \mathrm{bp}$ of $\mathrm{F}$ gene in nested RT-PCR (Table 2).

The results indicated that the 2 vaccines used, Aviffa ${ }^{\circledR}$ and Vaccine Nemovac $\AA$, were positive for $F$ gene by nested PCR. Both PCRs were positive either by using the 2 primer pairs "F $13 \mathrm{~B}+\mathrm{F} 11 \mathrm{~B}$ " that yielded a product of $489 \mathrm{bp}$, or by the nested primer pairs "F10B+F11B" that yielded a product of $408 \mathrm{bp}$ (Table 2). The eight samples (Giza-TRT-1, Giza-TRT-2, Giza-TRT-3, Giza-TRT-4, Giza-TRT-5, Beni-SuifTRT-7, Cairo-TRT-8 and Giza-TRT-10) were positive by RT-PCR for direct detection of aMPV and produced a specific 444 bp of $G$ gene using 2 sets of primers G1A+G5- and G1B+G5- and by the nested primer pairs G9B+G5- that yielded a product of 361 bp specific for $B$ subtype while they were negative using the nested primer pairs $\mathrm{G} 8 \mathrm{~A}+\mathrm{G} 5$ - that specific for A subtype (Table 2).

The results of nested PCR for $G$ gene indicated that the 2 vaccines used, Vaccine Aviffa ${ }^{\circledR}$ and Vaccine Nemovac ${ }^{\circledR}$, as well as samples (Giza-TRT-1, Giza-TRT-2, Giza-TRT-3, Giza-TRT-4, Giza-TRT-5, Beni-Suif-TRT-7, Cairo-TRT-8 and Giza-TRT-10) were positive for both PCRs using the 2 primer pairs "G1 A+G5- and G1B+G5-" that yielded a product of $444 \mathrm{bp}$ and by the nested primer pairs "G9B+G5-" that yielded a product of $361 \mathrm{bp}$ specific for B subtype while both vaccines tested negative using the nested primer pairs $\mathrm{G} 8 \mathrm{~A}+\mathrm{G} 5$ - that were specific for $\mathrm{A}$ subtype (Table 2 ). These results indicated that the 2 vaccines as well as those samples were related to $B$ subtype of aMPV. Samples TRT-6 and TRT-9 showed negative PCR results indicating that the virus is not the cause of the signs and there are other causes of respiratory disease in turkeys in these flocks.

\section{Results of Virus Isolation and Propagation}

The aMPV isolation and propagation was done in embryo chicken eggs via yolk sac inoculation route and further passed twice in Vero cells (Fig. 1). Virus isolation was completed for five out of the ten samples (Giza-TRT-1, Giza-TRT-3, Giza-TRT-4, Beni-SuifTRT-7 and Cairo-TRT-8). These five isolates were confirmed positive by RT-PCR for aMPV and produced a specific 489 bp of $\mathrm{F}$ gene. 


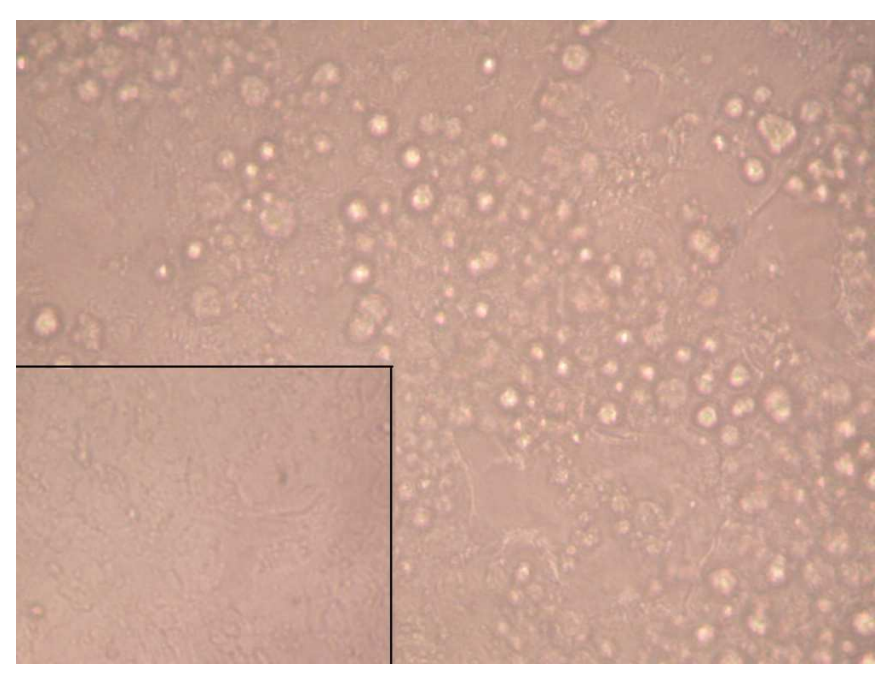

Fig. 1. Vero cells infected with aMPV of isolate Giza-TRT-4 after $72 \mathrm{~h}$ post infection, the infected cells showed vacculation, rounding and aggregations in comparison to normal non infected negative control at the lower left corner of the figure

Table 2. Results of RT-PCR for F gene and G gene

\begin{tabular}{|c|c|c|c|c|c|c|}
\hline Sample & $\begin{array}{l}\text { F gene } \\
\text { 1st PCR } \\
\text { F13B+F11B } \\
(489 \text { bp) }\end{array}$ & $\begin{array}{l}\text { Nested PCR } \\
\text { F10B+F11B } \\
(408 \text { bp) }\end{array}$ & $\begin{array}{l}\text { G gene } \\
\text { 1st PCR } \\
\text { G1A+G5 } \\
(444 \mathrm{bp})\end{array}$ & $\begin{array}{l}\text { G1B+G5 } \\
\text { (444 bp) }\end{array}$ & $\begin{array}{l}\text { Nested PCR } \\
\text { G8A+G5 } \\
(268 \mathrm{bp})\end{array}$ & $\begin{array}{l}\text { G9B+G5 } \\
(361 \mathrm{bp})\end{array}$ \\
\hline Vaccine Affifa ${ }^{\circledR}$ & + & + & + & + & - & + \\
\hline Vaccine Nemovac $\AA$ & + & + & + & + & - & + \\
\hline Giza-TRT-1 & + & + & + & + & - & + \\
\hline Giza-TRT-2 & + & + & + & + & - & + \\
\hline Giza-TRT-3 & + & + & + & + & - & + \\
\hline Giza-TRT-4 & + & + & + & + & - & + \\
\hline Giza-TRT-5 & + & + & + & + & - & + \\
\hline Beni-sueif-TRT-6 & - & - & / & / & / & / \\
\hline Beni-sueif-TRT-7 & + & + & + & + & - & + \\
\hline Cairo-TRT-8 & + & + & + & + & - & + \\
\hline Giza-TRT-9 & - & - & / & / & / & / \\
\hline Giza-TRT-10 & + & + & + & + & - & + \\
\hline
\end{tabular}

The $1^{\text {st }}$ PCR for F gene was done using primers F13B $+F 11 B$ with positive product of $489 \mathrm{bp}$, while the Nested PCR was done using primers F10B + F11B with positive product of $408 \mathrm{bp}$

\section{Results of Sequencing and Genetic Analysis}

The amplified part of the $\mathrm{F}$ and $\mathrm{G}$ genes from the field viruses were sequenced and compared with the other aMPV strains. (Fig. 2-6).

The nucleotide sequence analysis of the $\mathrm{F}$ gene revealed minor changes between field isolates and vaccine strains used in this analysis. The most characteristic change was reported in site 102 where it was " $\mathrm{T}$ " in vaccine strains while it was " $\mathrm{C}$ " in another field isolates, also G220A could differentiate only between Nemovac ${ }^{\circledR}$ and Aviffa ${ }^{\circledR}$ vaccine as well as other field strains but could not differaentiate between Aviffa ${ }^{\circledR}$ and other field isolates (Fig. 2). The only characteristic amino acid change was shown in position $74(\mathrm{E} 74 \mathrm{~K})$ of $\mathrm{F}$ gene that can differentiate Nemovac ${ }^{\circledR}$ than other strains in this analysis but not differentiate between Aviffa ${ }^{\circledR}$ and field isolates (Fig. 3)
The nucleotide percent identity between Egyptian isolate (Giza-TRT-4) and other field and vaccine strains from Europe for the $\mathrm{F}$ gene ranged from $98.5 \%$ to $98.9 \%$, while it was $99.6 \%$ and $99.8 \%$ of the 2 vaccines used in the comparison (Nemovac $\AA$ and Aviffa $\AA$ ), respectively and it was $99.1 \%$ with vaccine ancestor strain VCO3 (Fig. 4). These data indicate a close relatedness of Egyptian viruses to vaccine strains.

The nucleotide sequence comparison showed similarity of Egyptian isolates and characteristic single nucleotide change at position 107 (A) in comparison to aMPV (strain 6574) attachment protein $(\mathrm{G})$, while there was another change in position 270 ( $\mathrm{G}$ to $\mathrm{A}$ ) in the Egyptian isolates similar to strains $872 \mathrm{~S}$ and 6574 but different from other strains from Nigeria, Korea, Israel and Brazil (Fig. 5). The mutation at this site caused amino acid change at protein level from Glycine to Agrinine G/R in Egyptian viruses and in strain $672 \mathrm{~S}$ differentiating them from $\mathrm{VCO} 3$ strain and other strains (Fig. 6). 
strain-VCO3-60616 isolate French

isolate Hungarian 89

isolate Hungarian 97

isolate Italian

isolate United Kingdom

AVIFIA VACCINE

NEMOVAC VACCINE

Giza-TRT-2

Giza-TRT-5

Giza-TRT-10

Giza-TRT-4

Giza-TRT-1

Giza-TRT-3

\section{strain-VCO3-60616} isolate French isolate Hungarian 89 isolate Hungarian 97 isolate Italian isolate United Kingdom AVIFFA VACCINE NEMOVAC VACCINE

Giza-TRT-2

Giza-TRT-5

Giza-TRT-10

Giza-TRT-4

Giza-TRT-1

Gairo-TRT-8

strain-VC03-60616 isolate French isolate Hungarian 89 isolate Hungarian 97 isolate Italian

isolate United Kingdom AVIFFA VACCINE NEMOVAC VACCIN

Giza-TRT-2

Beni-suif-TRT-7

Beni-suif-TRT-7

Giza-TRT-

Giza-TRT-1

Giza-TRT-3

Cairo-TRT-8

strain-VCO3-60616

isolate French

isolate Hungarian 89

isolate Hungarian 97

isolate Italian

isolate United Kingdom

AVIFFA VACCINE

NEMOVAC VACCINE

Giza-TRT-2
Giza-TRT-5

Beni-suif-TRT-7

Giza-TRT-10

Giza-TRT-4

Giza-TRT-1

Giza-TRT-3

Cairo-TRT-8

strain-VCO3-60616
isolate French

isolate French

isolate Hungarian 97

isolate Hungaria

isolate United Kingdom

AVIFFA VACCINE

NEMOVAC VACCINE

Giza-TRT-4

Giza-TRT-1

Giza-TRT-3

Cairo-TRT-8

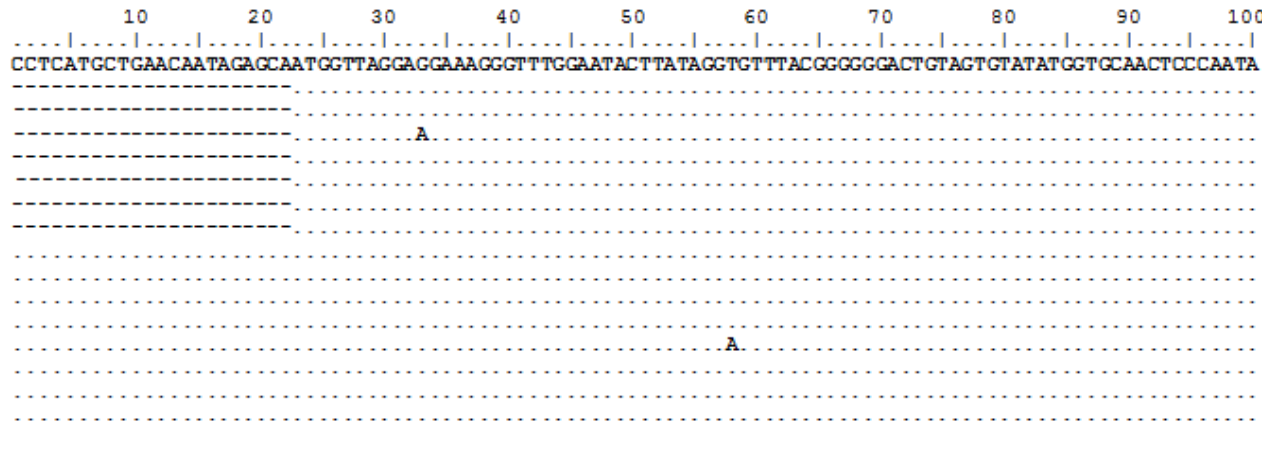

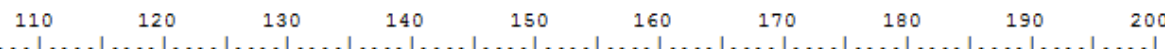
TTTGGAGTTATAGAGACACCC TGCTGGAGAGTGGTAGCT GCACCCC TCTGTAGACATGAGAGGGAGAGTTATGCTTGTCTGCTGCGGGAAGATCAGGGG

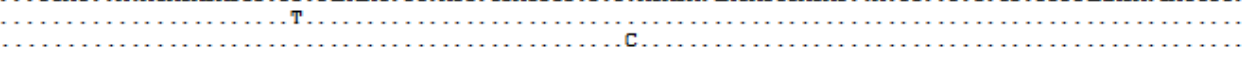

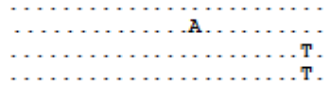
A GGTACTGCAC TAATGCAGGATCAACTGCTTACTACCCAAATGAAGA TGACT GCGAGGTAAGA GA TGACTATGT GTTCTGTGA TACT GCAGCAGGTATAAA

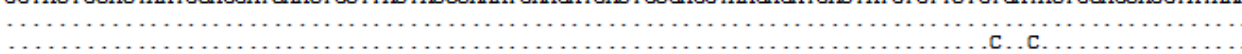

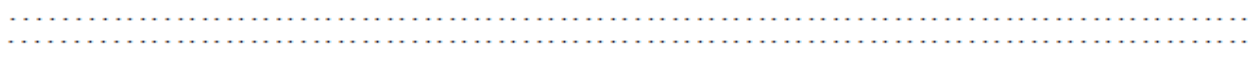
TGTTGCATCAGA GGTGGAGCAGTGCAACCAAAACA TA TCAACCTCTACTTACCCTTGCAAAGTTAGCACAGGGAGACACCCT GTAAGCATGGTAGCCT TA

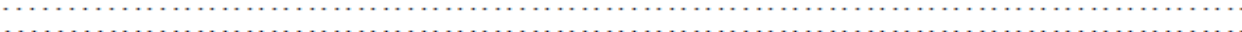

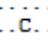

Fig. 2. Partial F gene nucleotides sequence comparison of field viruses of aMPV 


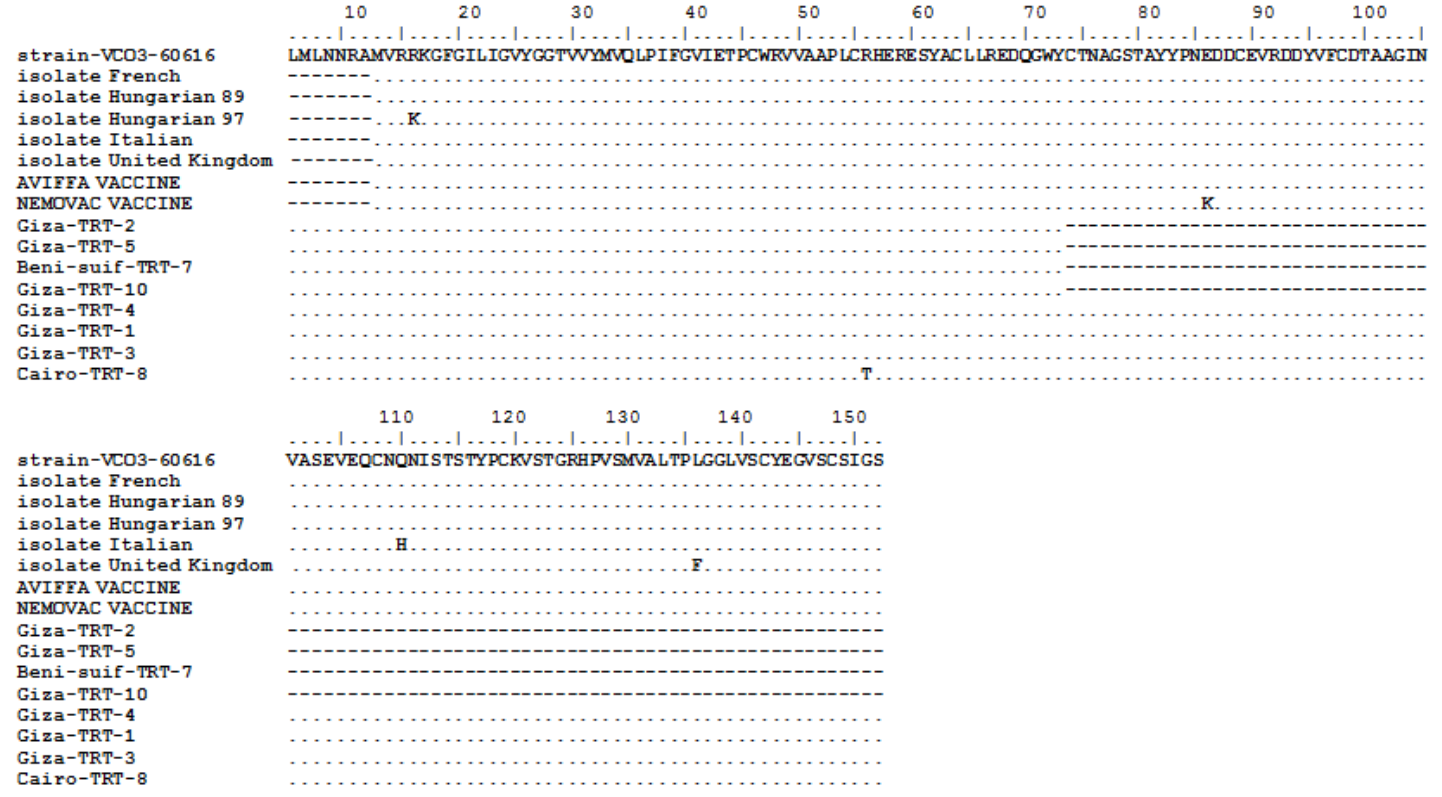

Fig. 3. Partial F gene amino acid sequence comparison of field viruses of aMPV

\begin{tabular}{|c|c|c|c|c|c|c|c|c|c|c|c|}
\multicolumn{10}{c|}{ Percent Identity } \\
\hline
\end{tabular}

Fig. 4. The percent identity of $\mathrm{F}$ gene nucleotides sequence comparison of field viruses of aMPV

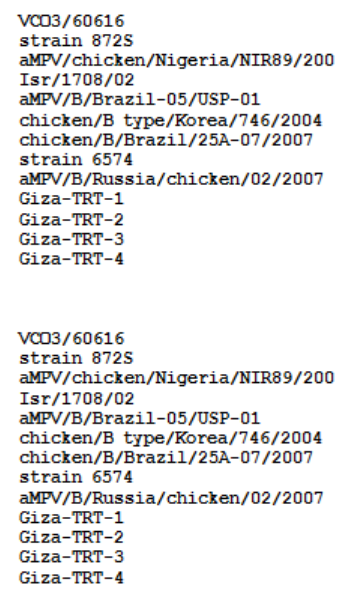




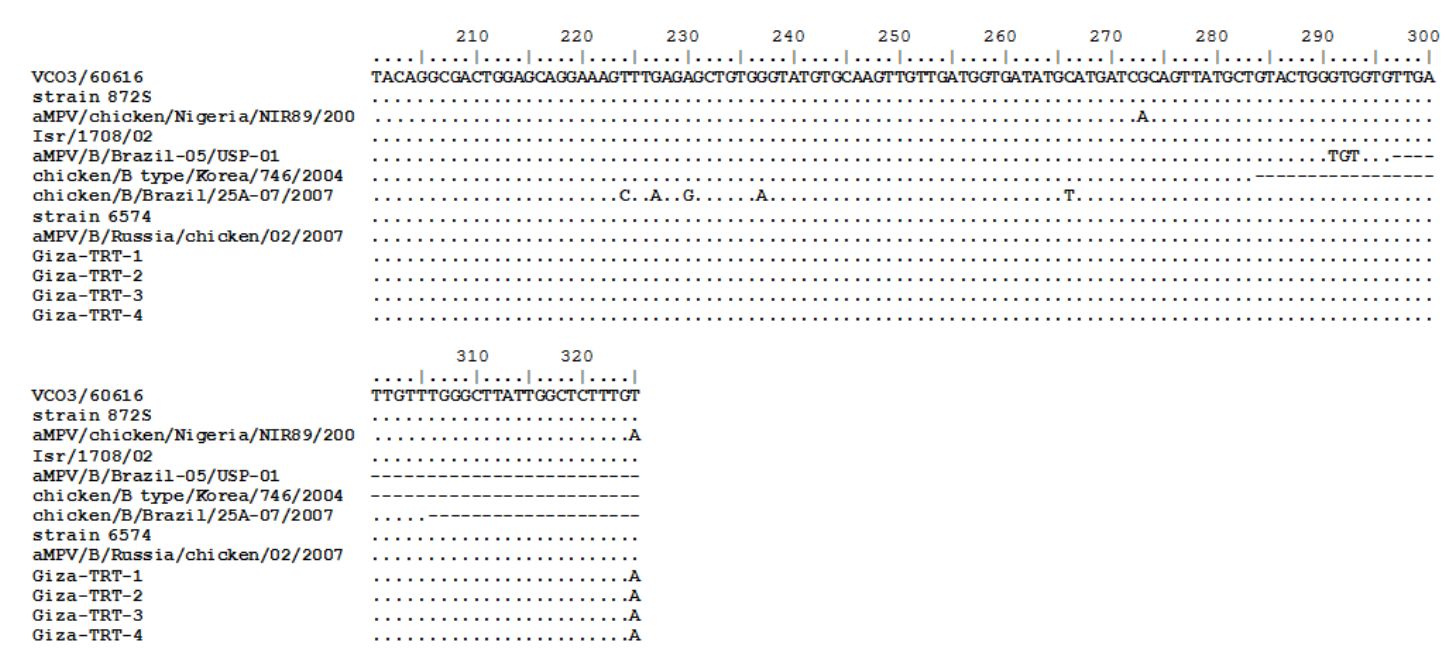

Fig. 5. Partial G gene nucleotide sequence comparison of field viruses of aMPV, the analysis was done based on attachment $G$ gene nucleotide sequences

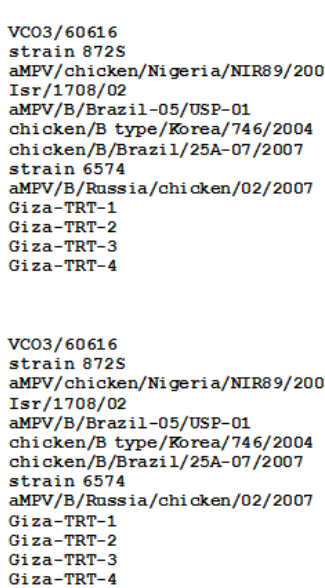

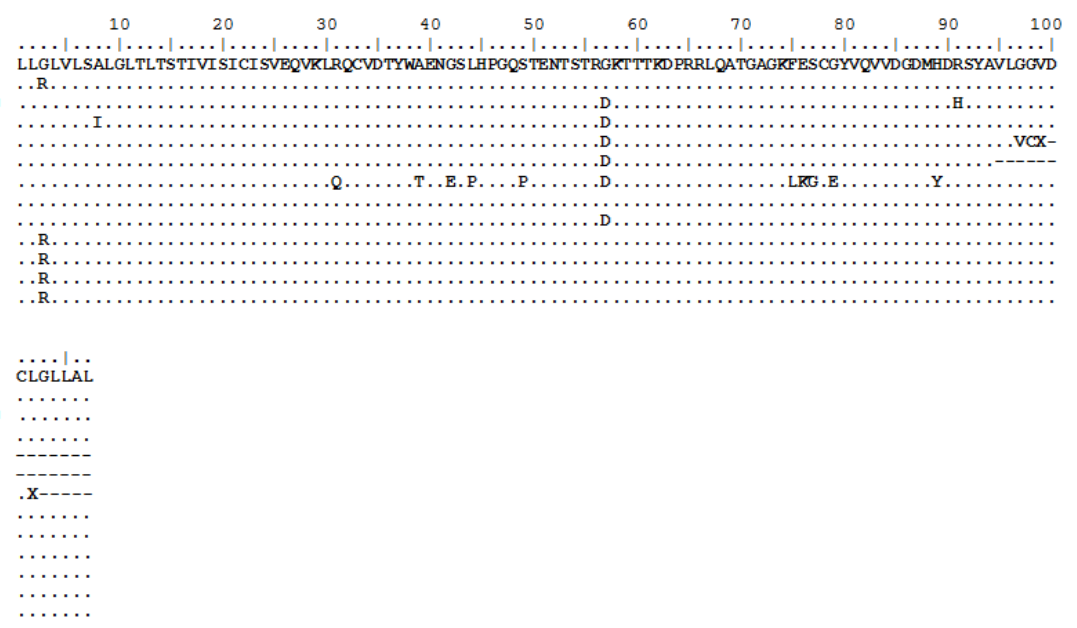

Fig. 6. Partial G gene amino acid sequence comparison of field viruses of aMPV, the analysis was done based on attachment G gene amino acid sequences

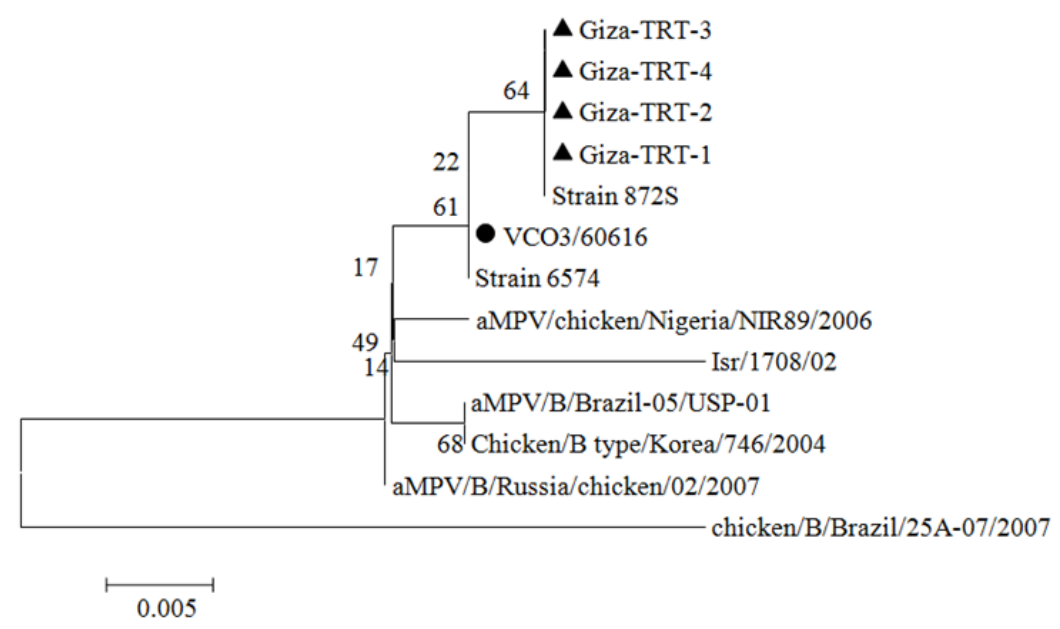

Fig. 7. Phylogenetic analysis of aMPV field isolates, the analysis was done based on fusion F protein 
Table 3. Estimates of evolutionary divergence between sequences

\begin{tabular}{|c|c|c|c|c|c|c|c|c|c|c|c|c|c|}
\hline & 1 & 2 & 3 & 4 & 5 & 6 & 7 & 8 & 9 & 10 & 11 & 12 & 13 \\
\hline \multicolumn{14}{|l|}{ 1. $\mathrm{VCO} 3 / 60616$} \\
\hline 2. strain 8725 & 0.00 & & & & & & & & & & & & \\
\hline 3. aMPV/chicken/Nigeria/NIR $89 / 2006$ & 0.01 & 0.01 & & & & & & & & & & & \\
\hline 4. Isr $/ 1708 / 02$ & 0.02 & 0.02 & 0.02 & & & & & & & & & & \\
\hline 5. aMPV/B/Brazil-05/USP-01 & 0.01 & 0.01 & 0.01 & 0.02 & & & & & & & & & \\
\hline 6. chicken/B type/Korea/746/2004 & 0.01 & 0.01 & 0.01 & 0.02 & 0.00 & & & & & & & & \\
\hline 7. chicken/B/Brazil/25A-07/2007 & 0.05 & 0.06 & 0.05 & 0.06 & 0.05 & 0.05 & & & & & & & \\
\hline 8. strain 6574 & 0.00 & 0.00 & 0.01 & 0.02 & 0.01 & 0.01 & 0.05 & & & & & & \\
\hline 9. aMPV/B/Russia/chicken/02/2007 & 0.00 & 0.01 & 0.00 & 0.01 & 0.00 & 0.00 & 0.05 & 0.00 & & & & & \\
\hline 10. Giza-TRT-1 & 0.00 & 0.00 & 0.01 & 0.02 & 0.01 & 0.01 & 0.06 & 0.00 & 0.01 & & & & \\
\hline 11. Giza-TRT-2 & 0.00 & 0.00 & 0.01 & 0.02 & 0.01 & 0.01 & 0.06 & 0.00 & 0.01 & 0.00 & & & \\
\hline 12. Giza-TRT-3 & 0.00 & 0.00 & 0.01 & 0.02 & 0.01 & 0.01 & 0.06 & 0.00 & 0.01 & 0.00 & 0.00 & & \\
\hline 13. Giza-TRT-4 & 0.00 & 0.00 & 0.01 & 0.02 & 0.01 & 0.01 & 0.06 & 0.00 & 0.01 & 0.00 & 0.00 & 0.00 & \\
\hline
\end{tabular}

The numbers of base substitutions per site from between sequences are shown. Analyses were conducted using the Maximum Composite Likelihood model (Tamura et al., 2004). The analysis involved 13 nucleotide sequences of aMPV G gene. Evolutionary analyses were conducted with MEGA6 (Tamura et al., 2013)

The alignment and percent identity of the G gene identified the highest similarity among Egyptian viruses (up to $100 \%$ ). The highest divergence was shown with chicken/B/Brazil/25A-07/2007 strain (6\%), while it was $2 \%$ with strain Isr/1708/02. The minimum divergence $(0.00)$ was obtained with strains 872S, 6574 and VCO3 (Table 3).

The phylogenetic tree revealed clustering of Egyptian viruses with strains $872 \mathrm{~S}$ and 6574 and somewhat differentiated from other related B subtype strains used in comparison of $\mathrm{G}$ gene sequencing analysis (Fig. 7).

\section{Discussion}

The aMPV causes problems in both turkeys and chickens due to moderate to acute respiratory tract infection with a sudden onset and rapid spread through flocks. Based on genetic and serological properties, aMPV can be classified into four distinct subgroups A, $\mathrm{B}, \mathrm{C}$ and D (OIE, 2008). The first of B subtype of aMPV was isolated in Europe in 1986 from France. However, the aMPV isolated in the UK in the previous year was A subtype. Subsequently, in 1988 and 1989, aMPV B subtype strains were isolated in Italy, Hungary and Spain. B subtype of aMPV was not detected in the UK until 1994 (Naylor et al., 1997). Furthermore, many reports described the detection of A and B subtypes (Cook and Cavanagh, 2002) of aMPV from turkeys and chickens in the Middle East, Asia and Africa.

This work aimed to characterize aMPV from infected turkey flocks in Egypt based on partial sequencing of $F$ and $G$ genes and to differentiate between field and vaccine strains. In this study, aMPV was detected in 8 samples collected from 3 governorates in Egypt (Giza, Beni-Suif and Cairo) from clinically suspected turkey farms. These samples tested positive by RT-PCR for F and $G$ genes. Virus isolation was successful for five isolates through inoculation in chicken eggs and on Vero cells. Further molecular detection using RT-PCR for G and $\mathrm{F}$ genes confirmed the five positive isolates of avian metapneumovirus. Analysis of nucleotide sequence relatedness of viral strains of aMPV indicates that the Egyptian viruses were very closely related to each other. The data indicated that these viruses belong to B subtype viruses isolated from Europe. These results raised the concern about vaccination against aMPV and vaccine use in the field. The results suggested that the aMPV was spreading in Egypt over the years due to continuous exposure to aMPV from respiratory illness in the examined farms. However the results are not sufficient to study disease prevalence, but they indicate wide spread nature of infection as the examined farms were distributed in 3 different governorates at middle and middle-south part of Egypt.

The nucleotide sequence comparison for both $\mathrm{F}$ and $\mathrm{G}$ genes revealed that the Egyptian viruses have highest similarities among each other. The presence of characteristic single nucleotide change in the Egyptian viruses at position 107 (A) in comparison to strain 6574 attachment $G$ protein, while there was another change in position 270 ( $\mathrm{G}$ to $\mathrm{A}$ ) similar to strains $872 \mathrm{~S}$ and 6574 but different from other strains from Nigeria, Korea, Israel and Brazil. This G/A mutation at position 7 of the $\mathrm{G}$ gene (Fig. 5) was recently identified as a marker for the AVIFFA/VC03 vaccine (Listorti et al., 2014). They showed that an $\mathrm{A}$ rather than $\mathrm{T}$ at this position was characteristic of the field strain $\mathrm{VC} 03$ being converted to its derived VC03 vaccine (Aviffa/Rhinovax).

Another two $\mathrm{VC} 03$ vaccine/progenitor marker positions (3210 and 3391) (Listorti et al., 2014) were also found indicating a greater certainty that the Egyptian viruses were indeed VC03 vaccine derived.

Some researchers indicated that very few mutations are needed to establish or remove attenuation from vaccine strain (Catelli et al., 2006). In another study for 
comparison of nucleotide (nt) and predicted amino acid (aa) sequences of parental pathogenic strain VCO3/60616 with the attenuated vaccine strain VCO3/50 revealed higher homology with aMPV A subtype virus (Sugiyama et al., 2010), they characterize a total of $18 \mathrm{nt}$ and 10 deduced aa differences between the strains and concluded that one or a combination of several differences could be associated with attenuation of VCO3/50. In this study, the most obvious amino acid changes were noticed in sites G31R and D85G (the numbering from the start codon of the $G$ gene and displayed in Fig. 6 as partial sequencing started from AA29) where the Egyptian isolates shared together with strain VCO3 and $872 \mathrm{~S}$ in site 31 and with strain 6574 in site 85 and differentiated from other related B subtype stains from Nigeria, Israel, Korea and Brazil (Fig 6).

In previous work, Serine residue in the $G$ proteins and lysine residue in the $\mathrm{F}$ protein were found to be exclusive to some field Italian viruses, indicating that those viruses probably originated within Italy and evolved from earlier Italian progenitors (Cecchinato et al., 2010). They also indicated that the Italian field viruses evolved in response to selection pressure from vaccine induced immunity.

The phylogenetic tree indicates clustering of the Egyptian field isolates with other European strains with a slight deviation from the vaccine strains indicating that these field isolates may have a common progenitor originated from vaccine strains.

The percent identity between each other and the vaccine strains (Aviffa ${ }^{\circledR}$ and Nemovac $($ ) was very high (more than 99\%) indicating high homology between field and vaccine strain used.

Ongor et al. (2010) detected 36 positive samples and they all belonged to $B$ subtype by molecular genotyping using primers specific to the attachment glycoprotein $(G)$ gene. Partial sequence analysis of DNA of those samples showed 95\% homology between the field type and the reference strain aMPV B subtype. Whereas clinically healthy turkeys were vaccinated with A subtype virus vaccine, the flocks with respiratory problems were vaccinated with $B$ subtype virus vaccine (Ongor et al., 2010).

The field reversion to virulence of live vaccines is more likely to occur in avian than in other species because opportunities for horizontal transfer of vaccines have increased a lot due to the higher numbers of vaccination. Some other reports revealed aMPV vaccine reversion to virulence in turkeys, the disease was observed at 3 weeks of age, which was shown to be caused by a vaccine derived reverting virus (Catelli et al., 2006) and in that instance, the flocks had been vaccinated at one day of age with the same live A subtype vaccine. At the same time, there was a detailed report about another Italian A subtype aMPV isolated during a turkey rhinotracheitis outbreak on a large farm of seven-week-old male turkeys which had only been vaccinated with B subtype vaccine on the seventh day of birth (Lupini, 2011).

In this study, we characterized these vaccine-derived viruses from different vaccination regimens as well as from non-vaccinated flocks which are very close to other infected flocks indicating circulation of these viruses in the field and they were capable of infecting turkeys and incurring the disease. All vaccination regimens contained at least one live vaccine from B subtype and this supports the idea that these filed viruses were originated from vaccine progenitor.

The sequence analysis of the Egyptian viruses clearly showed they were derived from vaccine of the B subtype applied in the field and indicated evidence of reversion of attenuated vaccine virus to virulence. This explanation was also described by others (Catelli et al., 2006) that the vaccine virus is residing in the poults in some region beyond the immediate upper respiratory tract. It may be relevant to note that after some researchers applied an attenuated aMPV which was almost identical to the A subtype vaccine, it could not be detected up to 3 weeks later, turkeys were shown to be fully protected against virulent challenge (Naylor et al., 1998). Virus detections were much later at about 2-5 weeks post vaccination. A previous study showed that when the same vaccine was tested for reversion to virulence trials in experimental conditions, disease was seen after 4 to 10 back passages (Naylor and Jones, 1994). In addition, multiple use of vaccines has adverse effects on their efficacy (Ganapathy et al., 2006).

\section{Conclusion}

The genotyping analysis and phylogenetic analysis based on F and G genes indicate that the Egyptian field viruses are very similar to the European strains of $B$ subtype of aMPV but with slight deviation from the vaccine strains. This indicates that these field isolates may have a common progenitor originated from vaccine strains. This is the first report describing the emergence of vaccine-derived mutants from the B subtype aMPV in broiler turkey farms in Egypt. This work also shed some light on possible reversion of attenuated vaccine viruses to virulence through their passages in the field.

\section{Acknowledgment}

The authors would like to acknowledge the Science and Technology Development Fund (STDF), national academy of science, Egypt, project: ID244 for the financial support.

\section{Author Contributions}

The authors contributed to this work as follows:

Abdel-Satar Arafa: $\mathrm{He}$ is the corresponding author and he designed, followed up and reviewed all the technical work and he prepared the manuscript. 
Wessam Mady: She is the person on charge for laboratory technical work.

Ahmed Hussein, Sabry Tamam and Hanafy Madbouly: They were sharing sample processing, field observations and they approved, reviewed and followed up the work.

\section{Conflicts of Interest}

The authors declare no conflict of interest.

\section{References}

Anon, 1985. Turkey rhinotracheitis of unknown aetiology in England and Wales. Preliminary report from the British veterinary poultry association. Veterinary Record, 117: 653-654.

Bayon-Auboyer, M.H., C. Arnauld, D. Toquin and N. Eterradossi, 2000. c-A/non-B avian Pneumoviruses (APV) reveal a novel APV subgroup. J. Gen. Virol., 81: 2723-2733.

Buys, S.B., J.H. Dv Preez and H.J. Els, 1989. The isolation and attenuation of a virus causing rhinotracheitis in turkeys in South Africa. Onderstepoort J. Vet. Res., 56: 87-98. PMID: 2748138

Catelli, E., M. Cecchinato, C.E. Savage, R.C. Jones and C.J. Naylor, 2006. Demonstration of loss of attenuation and extended field persistence of a live avian metapneumovirus vaccine. Vaccine, 24: 6476-6482. DOI: 10.1016/j.vaccine.2006.06.076

Cavanagh, D., K. Mawditt, P. Britton and C.J. Naylor, 1999. Longitudinal field studies of infectious bronchitis virus and avian pneumovirus in broilers using type-specific polymerase chain reactions. Avian Pathol., 28: 593-605. DOI: $10.1080 / 03079459994399$

Cecchinato, M., E. Catelli, C. Lupini, E. Ricchizzi and J. Clubbe et al., 2010. Avian Metapneumovirus (AMPV) attachment protein involvement in probable virus evolution concurrent with mass live vaccine introduction. Vet. Microbiol., 146: 24-34. DOI: $10.1016 /$ j.vetmic. 2010.04 .014

Collins, M.S. and R.E. Gough, 1988. Characterization of a virus associated with turkey rhinotracheitis. J. Gen. Virol., 69: 909-916. DOI: $10.1099 / 0022-1317-69-4-909$

Cook, J.K.A., M.M. Ellis, C.A. Dolby, H.C. Holmes and P.M. Finney, 1989a. A live attenuated turkey rhinotracheitis virus vaccine. 1. Stability of the attenuated strain. Avian Pathol., 18: 511-522. DOI: 10.1080/03079458908418624

Cook, J.K.A., H.C. Holmes, P.M. Finney, C.A. Dolby and M.M. Ellis, 1989b. A live attenuated turkey rhinotracheitis virus vaccine. 2. The use of attenuated strain as an experimental vaccine. Avian Pathol., 18: 523-534.

DOI: $10.1080 / 03079458908418624$
Cook, J.K.A. and M.M. Ellis, 1990. Attenuation of turkey rhinotracheitis virus by alternative passage in embryonated chicken eggs and tracheal organ cultures. Avian Pathol., 19: 181-186.

DOI: $10.1080 / 03079459008418668$

Cook, J.K., B.V. Jones, M.M. Ellis, J. Li and D. Cavanagh, 1993. Antigenic differentiation of strains of turkey rhinotracheitis virus using monoclonal antibodies. Avian Pathol., 22: 257-273. DOI: $10.1080 / 03079459308418919$

Cook, J.K.A., M.B. Huggins, S.J. Orvell and D.A. Senne, 1999. Preliminary antigenic characterization of an avian pneumovirus isolated from commercial turkeys in Colorado, USA. Avian Pathol., 28: 607-617. DOI: 10.1080/03079459994407

Cook, J.K. and D. Cavanagh, 2002. Detection and differentiation of avian pneumoviruses (metapneumoviruses). Avian Pathol., 31: 117-132. DOI: 10.1080/03079450120118603

Ganapathy, K., V. Todd, P. Cargill, E. Montiel and R.C. Jones, 2006. Interaction between a live avian pneumovirus vaccine and two different Newcastle disease virus vaccines in broiler chickens with maternal antibodies to Newcastle disease virus. Avian Pathol., 35: 429-434. DOI: $10.1080 / 03079450601007518$

Giravd, P., G. Bennejean, M. Guitret and D. Toquin, 1986. A possible viral candidate for the aetiology of turkey rhinotracheitis. Vet. Record, 118: 81. DOI: $10.1136 / v r .118 .3 .81-b$

Gough, R.E., 2003. Avian Pneumoviruses. In: Diseases of Poultry, Saif, Y.M. and H.J. Barnes (Eds.), Blackwell Publishing, USA, pp: 92-99.

Hafez, H.M., M. Hess, C. Prusas, C.J. Naylor and D. Cavanagh, 1980s. Presence of avian pneumovirus type a in continental Europe during the 1980s. J. Vet. Med., 47: 629-633. DOI: $10.1046 /$ j.1439-0450.2000.00398.x

Johnson, P.R., M.K. Spriggs, R.A. Olmsted and P.L. Collins, 1987. The $G$ glycoprotein of human respiratory syncytial viruses of subgroups A and B: Extensive sequence divergence between antigenically related proteins. Proceedings of the National Academy of Sciences, U.S.A. 84: 5625-562. DOI: $10.1073 /$ pnas.84.16.5625

Juhasz, K. and A.J. Easton, 1994. Extensive sequence variation in the attachment $(\mathrm{G})$ protien gene of avian pneumovirus: Evidence for two distinct subgroups. J. Gen. Virol., 75: 2873-2880.

DOI: 10.1099/0022-1317-75-11-2873

Listorti, V., C. Lupini, M. Cecchinato, P. Pesente and G. Rossi et al., 2014. Rapid detection of subtype B avian metapneumoviruses using RT-PCR restriction endonuclease digestion indicates field circulation of vaccine-derived viruses in older turkeys. Avian Pathol., 43: 51-6.

DOI: $10.1080 / 03079457.2013 .866212$ 
Lupini, C.A., 2011. Turkey rhinotracheitis outbreak caused by the environmental spread of a vaccinederived avian metapneumovirus. Avian Pathol., 40: 525-530. DOI: 10.1080/03079457.2011.607428

Mahmoud, A.H., H.A. Fahmy, A.M. Jehan, Gafer and A. Arafa, 2008. Investigation on turkey rhinotrachitis in commercial turkeys in Egypt. Proceedings of the 7th International Symposium on Turkey Diseases. (STD' 08), Berlin, Animal Health Research Institute, pp: 186-196.

Naylor, C.J. and R.C. Jones, 1994. Demonstration of a virulent subpopulation in a prototype live attenuated turkey rhinotracheitis vaccine. Vaccine, 12: 12251230. DOI: 10.1016/0264-410X(94)90248-8

Naylor, C., K. Shaw, P. Britton and D. Cavanagh, 1997. Appearance of type B avian pneumovirus in great Britain. Avian Pathol., 26: 327-338. DOI: $10.1080 / 03079459708419215$

Naylor, C.J., Britton, P. and D. Cavanagh, 1998. The ectodomains but not the transmembrane domains of the fusion proteins of subtypes A and B avian pneumovirus are conserved to a similar extent as those of human respiratory syncytial virus. J. Gen. Virol., 79: 1393-1398. PMID: 9634080

OIE, 2008. Terrestrial Manual, Turkey rhinotracheitis (avian metapneumovirus). Chapter 2.3.15.

Ongor, H., M. Karahan, R. Kalin, H. Bulut and B. Cetinkaya, 2010. Detection of avian metapneumovirus subtypes in turkeys using RT-PCR. Vet. Record, 166: 363-366. DOI: $10.1136 /$ vr.c1607
Sugiyama, M., H. Ito, Y. Hata, E. Ono and T. Ito, 2010. Complete nucleotide sequences of avian metapneumovirus subtype B genome. Virus Genes, 41: 389-395. DOI: $10.1007 / \mathrm{s} 11262-010-0518-\mathrm{z}$

Tamura, K., M. Nei and S. Kumar, 2004. Prospects for inferring very large phylogenies by using the neighbor-joining method. Proc. Nat. Acad. Sci., 101: 11030-11035. DOI: 10.1073/pnas.0404206101

Tamura, K., G. Stecher, D. Peterson, A. Filipski and S. Kumar, 2013. MEGA6: Molecular evolutionary genetics analysis version 6.0. Molecular Biol. Evolut., 30: 2725-2729. DOI: 10.1093/molbev/mst197

Tanaka, M., H. Tanuma, N. Kokumai, E. Oishi and T. Obi, 1995. Turkey rhinotracheitis virus isolated from broiler chicken with swollen head syndrome in Japan. J. Vet. Med. Sci., 57: 939-945. DOI: $10.1292 /$ jvms.57.939

Williams, R.A., C.E. Savage and R.C. Jones, 1991. Development of a live attenuated vaccine against turkey rhinotracheitis. Avian Pathol., 20: 45-55. DOI: $10.1080 / 03079459108418798$

Yu, Q., T. Barrett, T.D.K. Brown, J.K.A. Cook and P. Green, 1994. Protection against Turkey Rhinotracheitis pneumovirus (TRTV) induced by a fowlpox virus recombinant expressing the TRTV Fusion glycoprotein (F). Vaccine, 12: 569-573. DOI: $10.1016 / 0264-410 X(94) 90319-0$ 